644

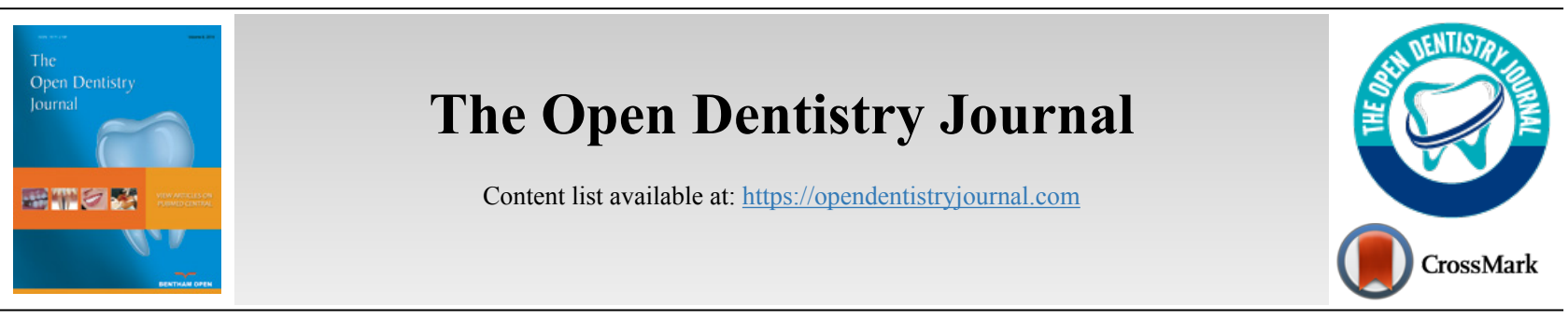

CASE REPORT

\title{
Surgical Orthodontic Treatment for Skeletal Class I with Facial Asymmetry and Occlusal Cant: A Case Report
}

\author{
Ryusuke Yamada ${ }^{1}$, Miki Okayama ${ }^{1}$, Shigehiro Takeda ${ }^{2}$, Tsuyoshi Shimo ${ }^{2}$ and Masahiro Iijima ${ }^{1, *}$ \\ ${ }^{1}$ Department of Oral Growth and Development, Division of Orthodontics and Dentofacial Orthopedics, School of Dentistry, Health Sciences \\ University of Hokkaido, Hokkaido, Japan \\ ${ }^{2}$ Department of Human Biology and Pathophysiology, Division of Reconstructive Surgery for Oral and Maxillofacial Region, Health Sciences \\ University of Hokkaido, Hokkaido, Japan
}

\begin{abstract}
:
Background:

Cases of facial asymmetry with chin deviation and canted occlusal plane represent a challenge in orthodontic treatment.

Case Report:

We report successful surgical orthodontic treatment for skeletal Class I with severe facial asymmetry. Miniscrew anchorage was used to decompensate the canted occlusal plane in presurgical orthodontic treatment with a fixed appliance by the intrusion of the maxillary right molars and extrusion of the left molars. Then, orthognathic surgery consisting of bilateral sagittal split osteotomy for asymmetric mandibular setback was performed. Treatment resulted in marked improvement of facial asymmetry.

Conclusion:

The use of miniscrew implant anchorage may represent a superior presurgical orthodontic treatment and expand the possibility of treatment by onejaw surgery.
\end{abstract}

Keywords: Facial asymmetry, Occlusal plane cant, Miniscrew implant anchorage, Surgical orthodontic treatment, Class III malocclusion, Molars.

\begin{tabular}{|l|l|l|l|}
\hline Article History & Received: May 18, 2021 & Revised: October 01, 2021 & Accepted: October 11, 202 \\
\hline
\end{tabular}

\section{INTRODUCTION}

Cases of facial asymmetry with dental midline and chin deviations represent challenges in orthodontic treatment [1]. The facial and dental midline have an essential role in facial esthetics [2], and their deviation is one of the typical features of facial asymmetry cases. The facial asymmetry cases are frequently associated with not only mandibular deformation but also maxillary deformation [3, 4]. Frontal occlusal plane canting of the maxilla is a common finding in patients with facial asymmetry $[5,6]$. Therefore, nongrowing patients with severe facial asymmetry should be treated using a combined orthodontic/orthognathic two-jaw surgical approach rather than a mandibular one-jaw surgical approach or orthodontic camouflage to achieve significant correction of the craniofacial asymmetry [6 - 8].

\footnotetext{
* Address correspondence to this author at the Department of Oral Growth and Development, Division of Orthodontics and Dentofacial Orthopedics, School of Dentistry, Health Sciences University of Hokkaido, Hokkaido, Japan; Tel: +81-133-23-2977; E-mail:iijima@hoku-iryo-u.ac.jp
}

The use of a Temporary Anchorage Device (TAD), such as a miniplate or miniscrew implant, has been widely accepted in clinical orthodontics $[9,10]$. The orthodontic treatment using $\mathrm{TAD}$ enables extensive tooth movement, including molar intrusion and distalization [11], which are extremely difficult to achieve with conventional fixed appliances alone. Therefore, presurgical orthodontic treatment with fixed appliances combined with the use of TAD may expand treatment options. Recent case reports have described the successful use of a miniscrew implant to correct a canted maxillary occlusal plane in conjunction with orthodontic/orthognathic surgery therapy $[12,13]$. If the maxillary asymmetry is limited to a mildly canted occlusal plane, correcting the occlusal plane using a fixed appliance combined with miniscrew implant anchorage makes minimally invasive treatment possible by simpler onejaw mandibular surgery rather than complex mandibularmaxillary two-jaw surgery.

In this case report, we describe successful surgical orthodontic treatment for skeletal Class I with severe facial 
asymmetry. Miniscrew implant anchorage was used to decompensate the dental arch tipping and canted occlusal plane as presurgical orthodontic treatment. Then, orthognathic surgery consisting of Bilateral Sagittal Split Osteotomy (BSSO) for asymmetric mandibular setback was performed.

\section{CASE REPORT}

\subsection{Diagnosis and Etiology}

The patient was a girl aged 20 years and 5 months who came for orthodontic treatment with chief complaints of anterior open bite and facial asymmetry (Fig. 1). The patient had no relevant family history and no medical or dental history of dental trauma. She had a straight profile and severe mandibular deviation toward the left according to the mandibular deformation in addition to occlusal plane canting and transverse dental compensation. The soft tissue vertical reference line was constructed as the line perpendicular to the interpupillary line [14]. The maxillary dental midline and the mandibular dental midline were deviated $1.5 \mathrm{~mm}$ and $7.5 \mathrm{~mm}$ toward the left of the facial midline, respectively. The softtissue menton deviated $12.0 \mathrm{~mm}$ toward the left. Intraoral examination showed Angle Class III molar relationship on the right and Angle Class I molar relationship on the left with minor crowding of both dentitions. Overjet was $0.2 \mathrm{~mm}$, and the overbite was $-2.5 \mathrm{~mm}$.
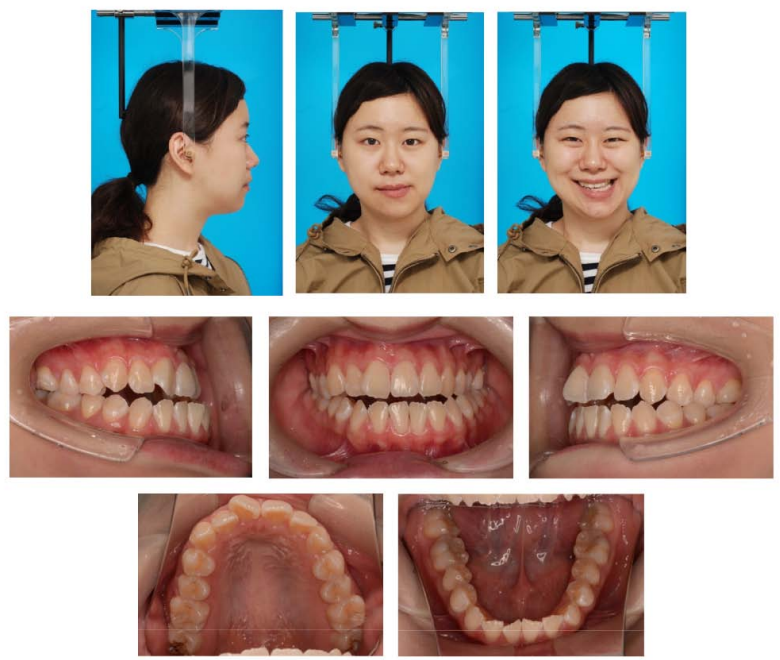

Fig. (1). Pretreatment facial and intraoral photographs.

Panoramic radiography showed no horizontal or vertical bone loss and normal root length (Fig. 2). The cephalometric assessment showed a skeletal class I relationship (ANB angle, $3.2^{\circ}$ ) (Table 1) with a high mandibular plane angle (FMA, $35^{\circ}$ ) and occlusal plane angle (Occ plane to $\mathrm{FH}, 15.0^{\circ}$ ). The mandibular and maxillary incisor inclinations were normal (FMIA, 56.2 ${ }^{\circ}$; U1-FH, $113.6^{\circ}$ ). Computed tomography (CT) imaging showed marked menton deviation to the left (13.5 $\mathrm{mm}$ ) (Fig. 3 and Table 2) and dental asymmetry associated with occlusal plane cant (bilateral differences in tooth height: $\mathrm{U} 3-\mathrm{H}, 0.9 \mathrm{~mm}$; U6MB-H, $3.3 \mathrm{~mm}$ ). In addition, the bilateral differences in coronal ramus angle (coronal ramus angle, $10.3^{\circ}$ ) and ramus position (Rma-S, $13.6 \mathrm{~mm}$ ) were significant [15].
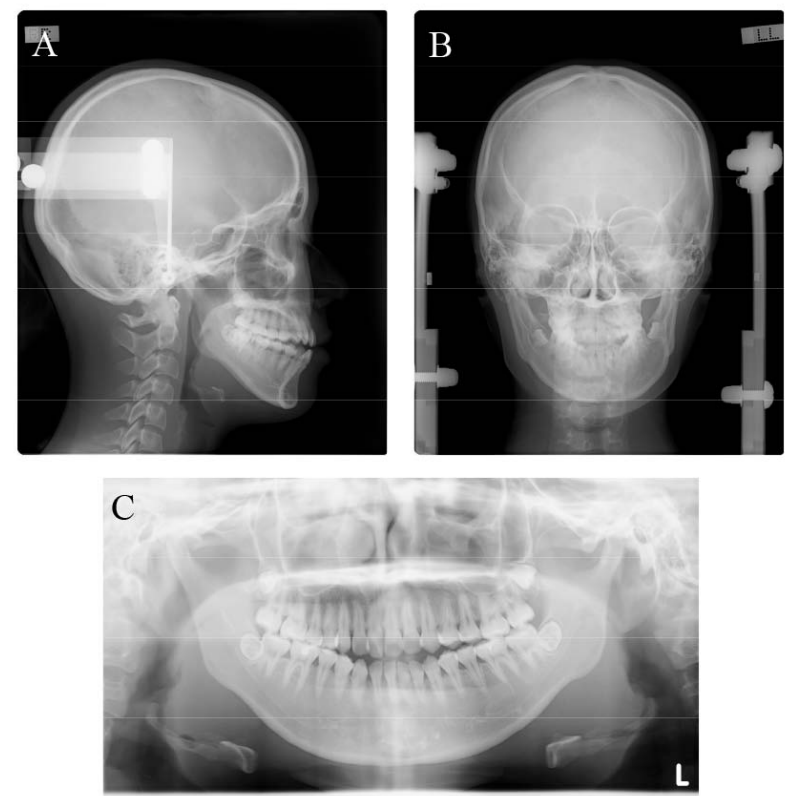

Fig. (2). (A) Pretreatment lateral cephalogram. (B) Posteroanterior cephalogram. (C) Panoramic radiograph.
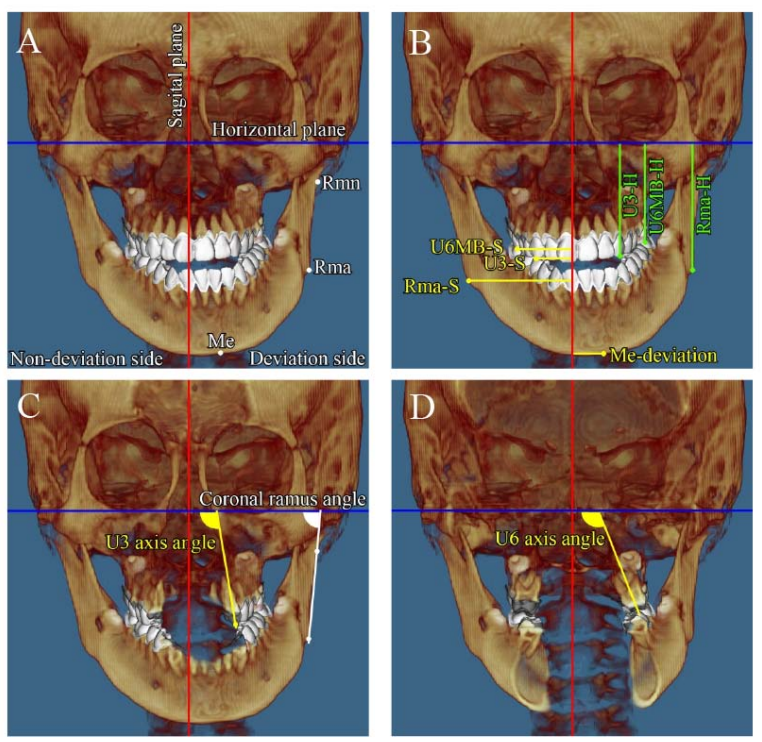

Fig. (3). Landmarks and measurement items used in the study. (A) Skeletal landmarks in frontal view. (B) Skeletal and dental measurements in frontal view. Me-deviation, Menton deviation; Rma$\mathrm{S}$, distance from Rma to midsagittal plane; U3-S, distance from canine tip to midsagittal plane; U6MB-S, distance from mesiobuccal cusp tip of first molar to midsagittal plane; Rma-H, distance from Rma to horizontal plane; U3-H, distance from canine tip to horizontal plane; U6MB-S, distance from mesiobuccal cusp tip of first molar to horizontal plane. (C) Skeletal and dental measurements in frontal view. U3 axis angle, medial angle between U3 axis and horizontal plane; coronal ramus angle, medial angle between horizontal plane and the line connecting Rmn and Rma. (D) U6 axis angle, medial angle between U6 axis and horizontal plane. 
Table 1. Summary of cephalometric mesurements.

\begin{tabular}{|c|c|c|c|c|}
\hline Variables & Mean & SD & Pre-Treatment (T1) & Post-Treatment (T2) \\
\hline SNA (degree) & 82.5 & 3.7 & 81.8 & 81.8 \\
\hline SNB (degree) & 79.2 & 3.7 & 78.6 & 56.8 \\
\hline ANB (degree) & 2.8 & 0.8 & 3.2 & 35.8 \\
\hline FMA (degree) & 27.3 & 3.1 & 35.0 & 111.6 \\
\hline U1-FH (degree) & 115.3 & 6.0 & 113.6 & 92.1 \\
\hline L1-MP (degree) & 95.5 & 3.1 & 89.1 & 53.6 \\
\hline FMIA (degree) & 57.2 & 3.9 & 56.2 & 13.5 \\
\hline FH-OC (degree) & 8.8 & 3.4 & 15.0 & 2.0 \\
\hline Overjet (mm) & 2.8 & 1.0 & 0.2 & 1.3 \\
\hline Overbite (mm) & 2.2 & 1.1 & -2.5 & \\
\hline
\end{tabular}

\subsection{Treatment objectives}

We made a diagnosis of skeletal class I malocclusion with mandibular deviation along with the maxillary canted occlusal plane. Treatment was performed to correct the facial appearance, improve the skeletal asymmetry, and establish appropriate incisor and molar relationships.

\subsection{Treatment Alternatives}

To achieve the treatment objectives, two possibilities were considered and discussed with the patient.

The first alternative involved combined fixed orthodontic treatment and orthognathic surgery by LeFort I osteotomy to correct the canted occlusal plane combined with BSSO for the asymmetric mandibular setback and maxillary first premolar extraction on both sides to correct maxillary incisor crowding. Extraction of both mandibular third molars would be necessary.

The second alternative involved combined fixed orthodontic treatment and orthognathic surgery by BSSO for the asymmetric mandibular setback. Maxillary first premolar extraction on both sides to correct maxillary incisor crowding and miniscrew implant anchorage would be used to correct the canted occlusal plane. Extraction of both mandibular third molars would be necessary.

After the two treatment plans had been explained to the patient, she selected the second option and provided informed consent to proceed.

\subsection{Treatment Progress}

The mandibular third molars (teeth 38 and 48) were extracted under general anesthesia before orthodontic treatment. The mandibular teeth were bonded with preadjusted edgewise brackets $(0.022 \times 0.028$-inch slot $)$, and the mandibular teeth were leveled and aligned using sequential nickel-titanium alloy wires. After extraction of the maxillary first premolars, a 0.022-inch slot preadjusted edgewise appliance was bonded to the maxillary teeth, and leveling and alignment were started using sequential nickel-titanium alloy wires. Next, a miniscrew implant $1.6 \mathrm{~mm}$ in diameter and 6 $\mathrm{mm}$ in length (Dual-top Auto Screw III; Jeil Medical, Seoul, Korea) was placed in the buccal region between the right maxillary second premolar and first molar (Fig. 4). The maxillary canines were retracted using a $0.016 \times 0.022$-inch stainless steel wire with elastic chains by application of intrusive force $(250 \mathrm{~g}$ load). Then the maxillary incisors were retracted using sliding mechanics along a $0.018 \times 0.025$-inch stainless steel wire with nickel-titanium closed coil springs (250 g load). After presurgical orthodontic treatment for 26 months, orthognathic surgery with BSSO was performed. The mandible was asymmetrically set back $7.0 \mathrm{~mm}$ on the right side and $0 \mathrm{~mm}$ on the left side. Postsurgical orthodontic treatment was performed for 13 months, and then the fixed appliances were removed after a total treatment time of 3 years and 3 months (Fig. 5), and the patient received a maxillary wraparound retainer and mandibular bonded lingual retainer.
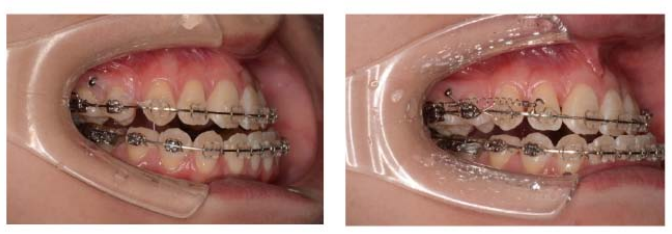

Fig. (4). Intraoral photographs. (A) Maxillary canine retraction using stainless steel wire by elastic chains with application of intrusive force. (B) Maxillary incisor retraction using sliding mechanics with nickeltitanium closed coil springs. During anterior retraction, the first molar and miniscrew implant were fixed with ligature wire as indirect anchorage mechanics.
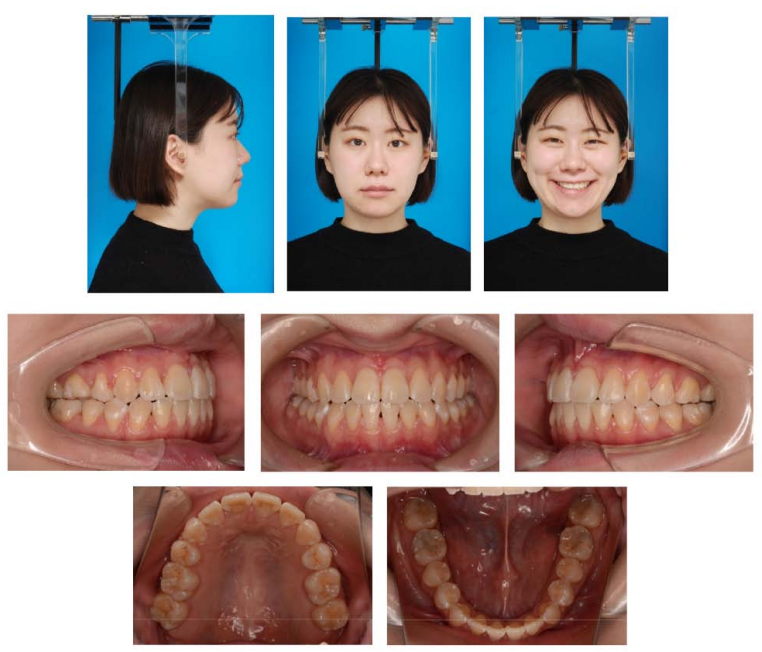

Fig. (5). Post-treatment facial and intraoral photographs. 


\subsection{Treatment Results}

The post-treatment records showed that the procedures resolved the occlusal cant and mandibular asymmetrical setback, improving the facial asymmetry (Fig. 5). The dental midlines were coincident with the facial midline, and proper class I canine relationships on both sides were achieved. The soft-tissue menton deviation was improved from $12.0 \mathrm{~mm}$ to 2 $\mathrm{mm}$ toward the left of the facial midline (Fig. 6). Panoramic radiography showed acceptable root paralleling without root resorption (Fig. 7). Cephalometric analysis (Fig. 7a and Table 1) and superimposition (Fig. 8) showed that a skeletal class I jaw relationship had been maintained (ANB angle, $5.0^{\circ}$ ), although the SNB angle was slightly decreased from $78.6^{\circ}$ to $76.8^{\circ}$ as a result of mandibular asymmetrical setback. The mandibular plane angle was increased slightly from $35.0^{\circ}$ to $35.8^{\circ}$ (FMA). The mandibular incisors were slightly proclinated from $56.2^{\circ}$ to $53.6^{\circ}$ (FMIA), and the maxillary incisors were slightly retroclinated from $113.6^{\circ}$ to $111.6^{\circ}$ (U1$\mathrm{FH})$.
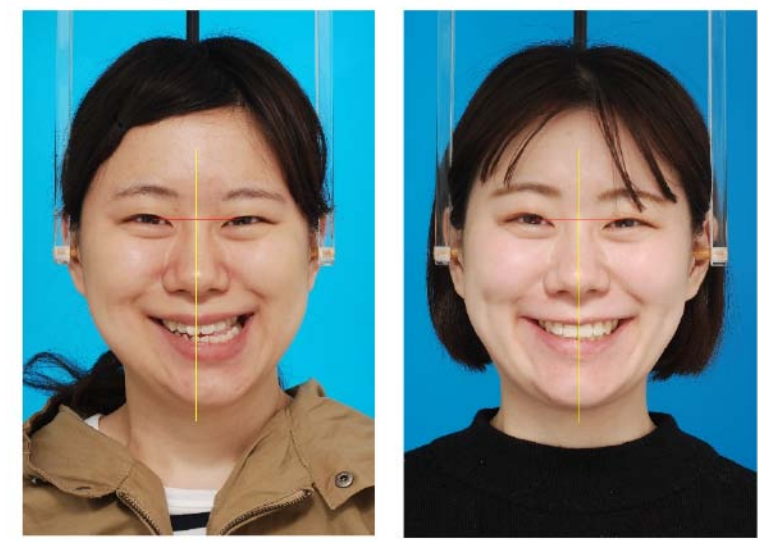

Fig. (6). Pretreatment and post-treatment facial photographs with facial midline.

The intrusion of the maxillary right dentition (N-side: U3H $0.4 \mathrm{~mm}$ canine intrusion, U6MB $1 \mathrm{~mm}$ molar intrusion) and extrusion of the left dentition (D-side: U3-H $0.6 \mathrm{~mm}$ canine extrusion, U6MB $2.1 \mathrm{~mm}$ molar extrusion) resolved occlusal plane canting, contributing to facial asymmetry. Significant improvements were also seen in coronal ramus angle $(\mathrm{N}$-side $78.0^{\circ}, \mathrm{D}$-side $80.9^{\circ}$ ) and ramus position (Rma-H: N-side 55.9 $\mathrm{mm}$, D-side $54.5 \mathrm{~mm}$ ) after orthognathic surgery with BSSO.
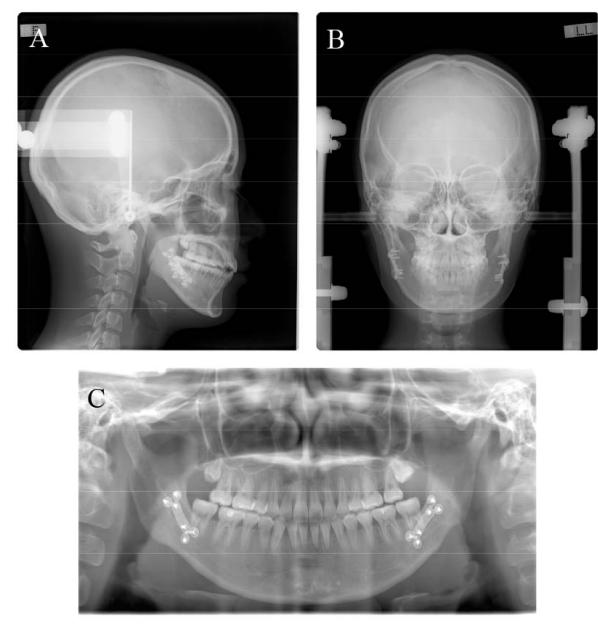

Fig. (7). (A) Post-treatment lateral cephalogram. (B) Posteroanterior cephalogram. (C) Panoramic radiograph.

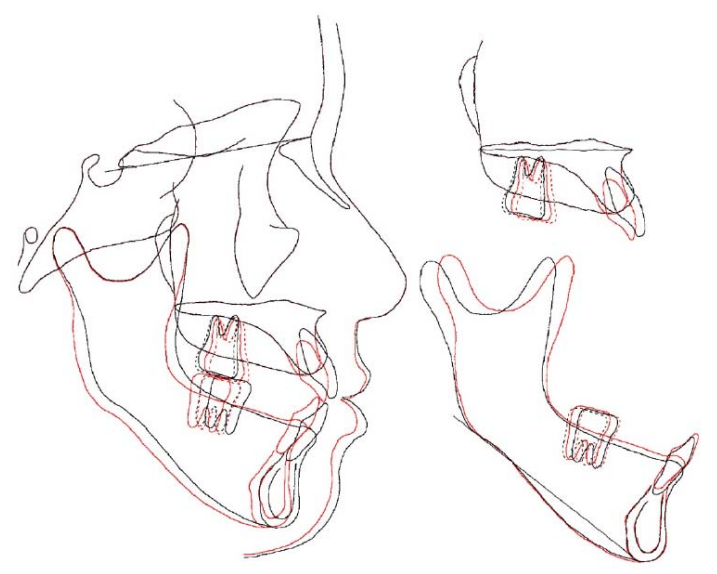

Fig. (8). Superimposed lateral cephalometric tracings: pretreatment, black line; post-treatment, red line.

Table 2. Summary of CT imaging assessment comparing nondeviation and deviation sides.

\begin{tabular}{|c|c|c|c|c|}
\hline- & \multicolumn{2}{|c|}{ Non-Deviation Side } & \multicolumn{2}{c|}{ Deviation Side } \\
\hline Variables & Pre-Treatment & Post-Treatment & Pre-Treatment & Post-Treatment \\
\hline Menton deviation (mm) & - & - & 13.5 & 3.8 \\
\hline Coronal ramus angle (degree) & 76.0 & 78.0 & 86.3 & 80.9 \\
\hline Rma-S (mm) & 41.6 & 45.4 & 55.2 & 48.4 \\
\hline Rma-H (mm) & 57.7 & 55.9 & 53.2 & 54.5 \\
\hline U3-S (mm) & 13.2 & 16.0 & 21.3 & 21.4 \\
\hline U3-H (mm) & 44.9 & 49.5 & 49.0 & 49.6 \\
\hline U3 axis angle (degree) & 96.2 & 100.7 & 104.6 & 103.2 \\
\hline U6MB-S (mm) & 21.5 & 23.8 & 30.9 & 28.5 \\
\hline U6MB-H (mm) & 46.2 & 45.2 & 42.9 & 45.0 \\
\hline U6 axis angle (degree) & 92.5 & 100.3 & 112.8 & 101.5 \\
\hline
\end{tabular}




\section{DISCUSSION}

The most common feature of facial asymmetry is the dental midline and menton deviations from the facial midline. A previous study classified the dental-facial midline according to the deviation of the maxillary and mandibular dental midline relative to the facial midline [2]. They found that the maxillary and mandibular dental midline were not coinciding in almost $3 / 4^{\text {th }}$ of their study subjects, as shown in the present case. In the present case, the combination treatment with fixed orthodontic treatment using miniscrew anchorage and orthognathic one-jaw surgery therapy markedly improved the dental-facial midline (both dental-midlines were coincident with the facial midline). In addition, the soft-tissue menton deviation was improved from $12.0 \mathrm{~mm}$ to $2 \mathrm{~mm}$ toward the left of the facial midline. A previous study reported that human sensitivity for perceiving facial imbalance increases when the skeletal deformation is close to or larger than $4 \mathrm{~mm}$ [4]. According to the results, it can be considered that the present treatment was effective in improving the dental-facial midline and menton deviations.

Facial asymmetry has a marked influence on physical appearance, and numerous dysmorphic syndromes are associated with severe mandibular asymmetry [16]. Such cases have multifactorial problems, including skeletal deformation and dental compensation [3, 4, 16]. Therefore, accurate evaluation of facial asymmetry by three-dimensional analysis with $\mathrm{CT}$ is required to achieve successful treatment outcomes $[6,17]$. In this case, detailed CT imaging showed severe facial asymmetry associated with occlusal plane cant (bilateral differences in tooth height; U3-H, $0.9 \mathrm{~mm}$; U6MB-H, $3.3 \mathrm{~mm}$ ), transverse dental compensation (bilateral difference in $\mathrm{U} 6$ axis angle: $20.3^{\circ}$ ), and mandibular deformation. Two-jaw orthognathic surgical approaches are usually used to treat facial asymmetry with severe maxillary deformation, including dental asymmetry [6-8]. As maxillary deformation in the present case was limited to a mildly canted occlusal plane and transverse dental compensation, a one-jaw surgery approach (BSSO) was applied to correct the mandibular facial asymmetry. The canted occlusal plane and transverse dental compensation were resolved by a combination of a fixed appliance with miniscrew implant anchorage during presurgical orthodontic treatment. A satisfactory treatment outcome with a symmetrical facial appearance was achieved.

The use of a miniscrew implant as anchorage has become widely accepted in clinical orthodontics in the last few decades $[9,10]$, enabling extensive tooth movement and expanding orthodontic treatment options [11]. This patient had severe facial asymmetry with mandibular deformation in addition to the occlusal plane canting and transverse dental compensation. Our presurgical orthodontic treatment with fixed orthodontic appliances combined with miniscrew anchorage allowed straightening of the transverse occlusal plane by the intrusion of the maxillary right dentition and extrusion of the maxillary left dentition. These changes would not have been possible without the anchorage. Therefore, the combined method was the best choice in the present case.

The use of miniscrew implant anchorage for presurgical orthodontic treatment enables minimally invasive approaches. The present case of facial asymmetry was treated through a simpler one-jaw mandibular surgery rather than a complex mandibular-maxillary two-jaw surgery. It is of great benefit to the patient if maxillary surgery is unnecessary, lowering the degree of surgical invasion as well as medical costs [18].

\section{CONCLUSION}

The combination treatment with fixed appliance using miniscrew anchorage and orthognathic one-jaw surgery is effective for patients with facial asymmetry and canted maxillary occlusal plane.

\section{ETHICS APPROVAL AND CONSENT TO PARTICIPATE}

Not applicable.

\section{HUMAN AND ANIMAL RIGHTS}

Not applicable.

\section{CONSENT FOR PUBLICATION}

Written informed consent was obtained from the patient for the publication of this case report, including accompanying images.

\section{STANDARD FOR REPORTING}

CARE guidelines and methodology were followed to conduct the study.

\section{AVAILABILITY OF DATA AND MATERIALS}

None.

\section{FUNDING}

None.

\section{CONFLICT OF INTEREST}

The authors declare no conflict of interest, financial or otherwise.

\section{ACKNOWLEDGEMENTS}

Declared none.

\section{REFERENCES}

[1] Proffit WR, Turvey TA. Dentofacial asymmetry.Contemporary treatment of dentofacial deformity. St. Louis: Mosby 2003; pp. 576-644.

[2] Niraula N, Acharya R, Humagain M. Dental-facial midline: An esthetic based classification. Open Dent J 2021; 15(Suppl-3, M4): 405-9.

[3] Thiesen G, Gribel BF, Kim KB, Freitas MPM. Maxillofacial features related to mandibular asymmetries in skeletal class III patients. J Oral Maxillofac Surg 2017; 75(5): 1015-25.

[http://dx.doi.org/10.1016/j.joms.2016.11.011] [PMID: 28012844]

[4] Thiesen G, Gribel BF, Freitas MPM, Oliver DR, Kim KB. Mandibular asymmetries and associated factors in orthodontic and orthognathic surgery patients. Angle Orthod 2018; 88(5): 545-51.

[http://dx.doi.org/10.2319/111517-785.1] [PMID: 29667467]

[5] Kwon SM, Baik HS, Jung HD, Jang W, Choi YJ. Diagnosis and surgical outcomes of facial asymmetry according to the occlusal cant and menton deviation. J Oral Maxillofac Surg 2019; 77(6): 1261-75. [http://dx.doi.org/10.1016/j.joms.2019.01.028] [PMID: 30794815]

[6] Kwon TG, Miloro M, Xi T, Han MD. Three-dimensional analysis of lip asymmetry and occlusal cant change after two-jaw surgery. J Oral 
Maxillofac Surg 2020; 78(8): 1356-65.

[http://dx.doi.org/10.1016/j.joms.2020.04.011] [PMID: 32428460]

[7] Georgalis K, Woods MG. A study of Class III treatment: Orthodontic camouflage $v s$ orthognathic surgery. Aust Orthod J 2015; 31(2): 138-48. [PMID: 26999886]

[8] Lee GC, Yoo JK, Kim SH, Moon CH. Lip line changes in Class III facial asymmetry patients after orthodontic camouflage treatment, onejaw surgery, and two-jaw surgery: A preliminary study. Angle Orthod 2017; 87(2): 239-45.

[http://dx.doi.org/10.2319/033016-254.1] [PMID: 27529732]

[9] Miyawaki S, Koyama I, Inoue M, Mishima K, Sugahara T, TakanoYamamoto T. Factors associated with the stability of titanium screws placed in the posterior region for orthodontic anchorage. Am J Orthod Dentofacial Orthop 2003; 124(4): 373-8.

[http://dx.doi.org/10.1016/S0889-5406(03)00565-1]

[PMID: 14560266]

[10] Park HS, Jeong SH, Kwon OW. Factors affecting the clinical success of screw implants used as orthodontic anchorage. Am J Orthod Dentofacial Orthop 2006; 130(1): 18-25.

[http://dx.doi.org/10.1016/j.ajodo.2004.11.032] [PMID: 16849067]

[11] Ding WH, Li W, Chen F, et al. Comparison of molar intrusion efficiency and bone density by CT in patients with different vertical facial morphology. J Oral Rehabil 2015; 42(5): 355-62.

[http://dx.doi.org/10.1111/joor.12261] [PMID: 25515652]

[12] Hashimoto T, Fukunaga T, Kuroda S, Sakai Y, Yamashiro T, TakanoYamamoto T. Mandibular deviation and canted maxillary occlusal plane treated with miniscrews and intraoral vertical ramus osteotomy: Functional and morphologic changes. Am J Orthod Dentofacial
Orthop 2009; 136(6): 868-77.

[http://dx.doi.org/10.1016/j.ajodo.2007.06.022] [PMID: 19962611]

[13] de la Iglesia F, Lopez A, Mareque J, Gutierrez J, Walter A, Puigdollers A. Correction of mandibular deviation and maxillary occlusal canting with mandibular "early" surgery and microscrews: Two case reports. Int Orthod 2019; 17(2): 384-94.

[http://dx.doi.org/10.1016/j.ortho.2019.03.021] [PMID: 31029533]

[14] Joh Y, Park HS, Yang HJ, Hwang SJ. Horizontal change of philtrum after orthognathic surgery in patients with facial asymmetry. Maxillofac Plast Reconstr Surg 2019; 41(1): 48.

[http://dx.doi.org/10.1186/s40902-019-0232-2] [PMID: 31799219]

[15] Chen YJ, Yao CC, Chang ZC, Lai HH, Yeh KJ, Kok SH. Characterization of facial asymmetry in skeletal Class III malocclusion and its implications for treatment. Int J Oral Maxillofac Implants 2019; 48(12): 1533-41.

[http://dx.doi.org/10.1016/j.ijom.2019.06.014] [PMID: 31235392]

[16] Yáñez-Vico RM, Iglesias-Linares A, Torres-Lagares D, GutiérrezPérez JL, Solano-Reina E. Three-dimensional evaluation of craniofacial asymmetry: An analysis using computed tomography. Clin Oral Investig 2011; 15(5): 729-36.

[http://dx.doi.org/10.1007/s00784-010-0441-7] [PMID: 20632049]

[17] Freudlsperger C, Rückschloß T, Ristow O, et al. Effect of occlusal plane correction on lip cant in two-jaw orthognathic surgery - A threedimensional analysis. J Craniomaxillofac Surg 2017; 45(6): 1026-30. [http://dx.doi.org/10.1016/j.jcms.2017.03.014] [PMID: 28446369]

[18] Panula K, Keski-Nisula L, Keski-Nisula K, Oikarinen K, Keski-Nisula S. Costs of surgical-orthodontic treatment in community hospital care: An analysis of the different phases of treatment. Int J Adult Orthodon Orthognath Surg 2002; 17(4): 297-306. [PMID: 12593002]

\section{(C) 2021 Yamada et al.}

This is an open access article distributed under the terms of the Creative Commons Attribution 4.0 International Public License (CC-BY 4.0), a copy of which is available at: https://creativecommons.org/licenses/by/4.0/legalcode. This license permits unrestricted use, distribution, and reproduction in any medium, provided the original author and source are credited. 